\title{
МОДЕЛИРОВАНИЕ ВЕРОЯТНОСТИ ДЕФОЛТА ИНВЕСТИЦИОННЫХ ПРОЕКТОВ
}

Моргунов А.В., ${ }^{1}$

В статье рассматриваются основные подходы, используемые при моделировании оценки вероятности дефолта инвестиционных проектов в коммерческом банке в рамках подхода, основанного на внутренних рейтингах (IRB Approach). Разработана модель оценки вероятности дефолта для сделок проектного финансирования на основании российской статистики с использованием эконометрической модели множественного выбора. Проведена валидация разработанной модели и модели, созданной ранее на основании дефолтной статистики.

Основными целями исследования являлись: анализ различных методов оценки вероятности дефолта инвестиционных проектов; практическое применение одного из основных методов - метода множественного выбора к российским инвестиционным проектам (ранее автором применялся метод бинарного выбора, результаты практического применения которого опубликованы в 2015 году в журнале Новой экономической ассоциации» №2(26)) и сопоставление методов бинарного и множественного выбора по результатам валидации данных моделей с использованием хорошо известных валидационных характеристик и критериев. В статье рассматриваются основные подходы, используемые при моделировании оценки вероятности дефолта инвестиционных проектов в коммерческом банке в рамках подхода, основанного на внутренних рейтингах (IRB Approach). Результаты исследования связаны с получением модели оценки вероятности дефолта для сделок проектного финансирования с помощью метода множественного выбора, обладающей высокой точностью (дискриминационной способностью) и стабильностью (t-критерий Стьюдента выполнен с доверительной вероятностью более 85\%) и получением количественного сопоставления качества разработанной модели множественного выбора с качеством разработанной ранее моделью бинарного выбора. Приведенные алгоритмы и модели могут быть использованы кредитными организациями при разработке рейтинговых моделей на основе внутренних рейтингов (IRB Approach). Целесообразность использования полученных результатов может быть проверена банками исключительно по итогам проведения валидации представленных моделей на своих собственных кредитных портфелях инвестиционных проектов. По результатам исследования сделан вывод о возможности применения методов бинарного и множественного выбора (точность полученных моделей - высокая) при оценке кредитоспособности инвестиционных проектов и сильном влиянии рискфактора IRR на кредитоспособность проектов. Однако оценить должным образом качество полученных моделей и гипотез на текущий момент не представляется возможным в связи с ограниченностью данных.

Ключевые слова: дефолт, модель бинарного выбора, модель множественного выбора, дискримиационная способность, калибровка, валидация

JEL: G21, G24, G32.

\section{Основные методы оценки вероятности дефолта проектов}

Модели оценки вероятности дефолта играют важную роль в системах риск-менеджмента коммерческих банков, так как позволяют осуществить оценку кредитоспособности для различных контрагентов и сделок. Внедрение в практику первого компонента Базель II предполагает использование продвинутого подхода оценки кредитоспособности кредитного портфеля с использованием внутренних рейтинговых моделей (IRB Approach) для оценки кредитного риска. Это требует разработки отдельных моделей для различающихся по экономической сущности и уровню принимаемого кредитного риска групп активов. В частности, многие российские банки испытывают сложности, связанные с разработкой моделей для сделок проектного финансирования. Проектное финансирование - это финансирование инвестиционных проектов, при котором источником обслуживания долговых обязательств являются денежные потоки, генерируемые самими проектами. Специфика этого вида инвестирования состоит в том, что

1. Аспирант НИУ ВшЭ. 
оценка затрат и доходов осуществляется с учетом распределения риска между участниками проекта. Достоинствами проектного финансирования являются:

- отсутствие прямых финансовых обязательств организаторов, что не влияет на достаточность капитала и рейтинги их основной деятельности;

- $\quad$ возможность разделить риски, включая политические, и долг, исключить ограничения по другим транзакциям инициатора проекта;

- $\quad$ формирование заинтересованности банков во вхождении в проектный синдикат на стадии его формирования;

- участие кредиторов в экспертизе проекта в ходе его реализации для оперативного предотвращения возможных убытков (Полтерович, 2010).

При этом имеются и проблемные моменты, связанные со сложностью определения рисков, повышенными рисками заемщиков в силу особенностей залогов, повышенной стоимостью ресурсов и пр.

Проведенные исследования показали, что сделки проектного финансирования имеют большую длительность, рассчитаны на более рискованных заемщиков, имеют более низкие кредитные спреды по сравнению с сопоставимыми синдицированными кредитами. Среди исследований в области проектного финансирования выделяются многие работы (Kayser, 2013; Laishram and Kalinidi, 2009; Gatti, 2013; Hait, 2011; Карминский, Моргунов и Богданов, 2015). При оценке кредитоспособности инвестиционных проектов на различных временных интервалах используются модели выживаемости, представленные в книгах (Кокс и Льюис, 1969; Кокс и Оукс, 1988).

Кайзер (Kayser, 2013) дан анализ публикаций по юридическим и договорным вопросам сделок проектного финансирования, оценкам рисков и выбору проектов, взаимодействию с государством в рамках различных проектов. Рассмотрено измерение рисков при оценивании как индивидуальных проектов, так и на основании портфельной оценки, приводятся подходы для оценивания спредов сделок политических компонентов и нефинансовых спонсорских контрактов.

В работе Лайшрам и Калиниди (Laishram and Kalinidi, 2009) показано, как использовать рейтинги при оценивании сделок проектного финансирования для механизма частно-государственного партнерства с помощью аналитических методов оценивания целесообразности проектов (Desirability Rating Analytical Tool, DRAT). Дополнительно рассмотрены возможности применения рекомендаций Базель II в части проектного финансирования, в том числе для облигаций на кредиты проектного финансирования, и особенности многокритериальных моделей принятия решений в условиях неопределенности.

В работе Гатти (Gatti, 2013) в главе 8 рассматриваются вопросы, связанные с оценкой кредитных рисков сделок проектного финансирования в соответствии с Базельскими соглашениями, приведены критерии оценивания и их использование при рейтинговании инвестиционных проектов на основе методологий рейтинговых агентств Standard \& Poors и Moody's. В работе сопоставляются уровни кредитного риска для сделок проектного финансирования и корпоративного кредитования, показывается, что проектное финансирование не является более рискованным в сравнении с корпоративным кредитованием. Основным недостатком методологий рейтинговых агентств является экспертный выбор как самих риск-факторов, влияющих на кредитоспособность инвестиционных проектов, так и их веса.

В исследовании Хаита (Hait, 2011) приведены подходы к построению симуляционных (имитационных) моделей, представляющих собой моделирование потоков платежей и обслуживание долга (дефолт возможен при отсутствии возможности обслуживания долга). Эти модели интересны для классификации рисков, а также при определении переменных, характеризующих проект. Классификация рисков включает коммерческие и страновые параметры проекта, риски использования оборудования и технологий реализации проекта и прочие. Соответству- 
ющие переменные могут быть использованы в моделях оценки кредитоспособности инвестиционных проектов при наличии информации по ним.

В статье Карминского и соавторов (Карминский, Моргунов и Богданов, 2015) приводится эмпирическое обоснование факторов кредитного риска инвестиционных проектов и их веса, основанное на дефолтной статистике (модели бинарного выбора - бинарная логистическая регрессия). В статье описываются этапы формирования выборки данных для разработки модели, преобразование риск-факторов с целью снижения влияния их экстремальных значений и сопоставимости на единой шкале в стандартных отклонениях. По результатам однофакторного анализа оценены дискриминационные способности отдельных преобразованных факторов риска и исключены факторы риска со слабой статистической значимостью. По результатам многофакторного анализа (с учетом результатов корреляционного анализа) определена наиболее точная модель, имеющая экономический смысл (основные гипотезы в отношении риск-факторов, входящих в модель, выполнены). В оптимальную модель вошло четыре фактора риска - IRR, «Доля собственного участия бенефициаров», «Индустриальный фактор» и «Региональный фактор». Дискриминационная способность модели составила 76,30\%. Наибольшим весом (42\%) в модели обладал риск-фактор IRR. Для возможности осуществлять оценку годовой вероятности дефолта с учетом требований (Basel, 2011) была произведена калибровка модели на годовую дефолтную частоту кризисного 2009 г. - 12,50\% (с учетом негативных тенденций в экономике России и принципа консервативности). На основании K-S-статистики (оптимальной доли корректно отсеченных дефолтных проектов и некорректно отсеченных недефолтных проектов) рассчитан балл отсечения и реализован алгоритм принятия решения о целесообразности участия в реализации инвестиционного проекта.

Для определения вероятности дефолта проекта в течение заданного периода времени $t$ при наличии достаточной дефолтной статистики может быть применена портфельная модель пропорциональных интенсивностей Кокса (Cox Proportional Hazards Model), которая представлена в работах английских ученых Кокса, Льюиса и Оукса (Кокс, Льюис, 1969; Кокс, Оукс, 1988). Согласно результатам данных работ, вероятность дефолта $P D(t)$ в момент времени $t$ вычисляется по следующей формуле:

$$
\begin{aligned}
& P D(t)=1-Q(t)^{e^{\beta^{T} \times x}}, \\
& \text { ггде } \\
& Q(t) \\
& \text { e } \\
& T \\
& t \\
& \text { - срок жизни инвестиционного проекта; }
\end{aligned}
$$

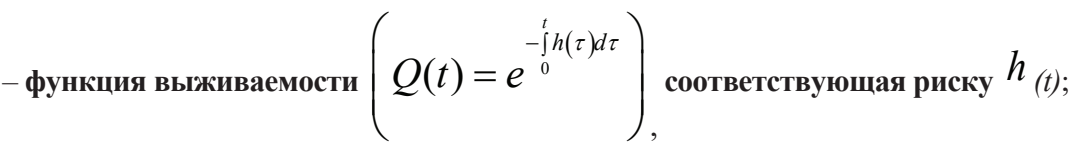

$$
\begin{aligned}
& \text { - здесь и далее по тексту - обозначение экспоненты; } \\
& \text { - здесь и далее по тексту - оператор транспонирования; } \\
& \beta \\
& \text { - вектор-строка регрессионных коэффициентов при нормализованных риск-факторах; } \\
& x
\end{aligned}
$$

Основным допущением в данной модели является то, что функция риска представляется в виде произведения: $h(x, t)=h_{0}(t) \times e^{\beta^{T} \times x}$, то есть не учитываются изменения нормализованных риск-факторов с течением времени. В связи с ограниченным количеством дефолтных проектов построение модели пропорциональных интенсивностей Кокса на текущий момент не представляется возможным. С другой стороны в будущем данная модель позволила бы оценивать вероятность дефолта на любом временном интервале (а не только на указанном горизонте), что является крайне полезным при прогнозировании поступления/непоступления денежных потоков по инвестиционным проектам и расчета резервов по международным стандартам с использованием полученных оценок. 
Малое количество дефолтных проектов (всего восемь штук), используемых при разработке модели бинарного выбора в статье Карминского и соваторов (Карминский, Моргунов, Богданов, 2015) не позволяет понять, насколько стабильными являются полученные оценки. В таких случаях обычно разрабатываются альтернативные модели - эконометрические модели множественного выбора, основанные на воспроизведении экспертного ранжирования рейтинговых агентств или кредитных экспертов (модель мультиномиальной логистической регрессии). Оптимальная из моделей бинарного и множественного выбора определяется по результатам валидации обеих моделей на последнем имеющемся временном срезе данных по проектам.

В настоящей статье приводится методология построения эконометрической модели множественного выбора. Для построения моделей множественного выбора ранжирование инвестиционных проектов было осуществлено по пяти основным рейтинговым категориям с учетом негативной информации, имеющейся за время жизни проектов (табл. 1):

Таблииа 1

Экспертное ранжирование

\begin{tabular}{|c|c|}
\hline $\begin{array}{c}\text { Экспертный рей- } \\
\text { тинг }\end{array}$ & Алгоритм отнесения \\
\hline 1 & Инвестиционный проект оказался в дефолте \\
\hline 2 & $\begin{array}{r}\text { По инвестиционному проекту (или проектным компаниям) за время жизни инвестиционного проекта } \\
\text { случались просрочки и реструктуризации платежей }\end{array}$ \\
\hline 3 & $\begin{array}{c}\text { По инвестиционному проекту не случалось просрочек и реструктуризаций, но существует значительная } \\
\text { вероятность их появления в будущем из-за изменений графика реализации инвестиционого проекта. } \\
\text { Имеется некоторая негативная информация по финансовому положению проектных компаний в теку- } \\
\text { щий момент }\end{array}$ \\
\hline 4 & $\begin{array}{c}\text { Просрочек и реструктуризаций по инвестиционному проекту не было. Проект выполняется по графику. } \\
\text { Присутствует какая-либо негативная информация относительно ухудшения финансового состояния про- } \\
\text { ектных компаний в будущем }\end{array}$ \\
\hline 5 & $\begin{array}{c}\text { Просрочек и реструктуризаций по инвестиционному проекту не было. Проект выполняется по графику. } \\
\text { Отсутствует какая-либо негативная информация по инвестиционному проекту }\end{array}$ \\
\hline
\end{tabular}

Полученные с использованием предлагаемой методологии результаты также будут приведены в настоящей статье. Дополнительно в статье приведена краткая методология по валидации моделей оценки кредитоспособности инвестиционных проектов и получены результаты ее применения в отношении моделей бинарного и множественного выбора. На основании предложенной методологии определена более точная модель.

Подводя итог вступительной части, хочу отметить, что в коммерческих банках на текущий момент могут использоваться четыре основных вида моделей для оценки вероятности дефолта инвестиционных проектов: модели бинарного выбора (бинарной логистической регрессии), модели множественного выбора (мультиномиальной логистической регрессии), симуляционные модели, модели пропорциональных интенсивностей Кокса (при достаточности дефолтной статистики). Наиболее используемыми являются модели бинарного выбора и модели множественного выбора. Это связано с наибольшей адекватностью и стабильностью данных моделей при оценке экономических взаимосвязей по сравнению с прочими видами моделей, а также тем фактом, что данные виды моделей и их методология известны регуляторам банковской деятельности в большинстве стран, поэтому обосновать целесообразность применения данных моделей регуляторам значительно проще, чем, например, в отношении симуляционных моделей.

\section{Методология построения модели оценки вероятности дефолта сделок проектного финансирования с использованием множественного выбора}

Представленный подход и построенные на его основе модели могут быть использованы как при принятии решения о целесообразности участия кредитной организации в реализации инвестиционного проекта, так и при оценке годовой вероятности дефолта (Basel, 2011) уже ре- 
ализуемых инвестиционных проектов, а также для кредитных портфелей проектного финансирования (Полтерович, 2010) с учетом особенностей структуры выборки по дефолтам и по отраслям.

\section{Методология, используемая при разработке модели}

Преемственность методологии исследования связана с использованием подходов к оценке вероятности дефолта (применение моделей множественного выбора в логит- и пробит-спецификациях, калибровка рейтинговых моделей, использование K-S-статистики при принятии решения об участии в проекте и прочие), используемых в предшествующих работах (Карминский, Моргунов и Богданов, 2015; Лобанов и Чугунов, 2009; Peresetsky, Karminsky и Golovan, 2011; Карминский и Фалько, 2013; Тотьмянина, 2014).

Под дефолтом инвестиционного проекта понимается наступление одного из следующих событий в течение срока реализации проекта (Basel, 2011; Банк России, 2012):

1. Дефолт хотя бы одной из проектных компаний (заемщиков), осуществляющих проект, то есть наличие хотя бы у одной компании, участвующей в проекте, одного из следующих признаков:

- Проектная компания признана несостоятельной (банкротом).

- Проектная компания является устойчиво неплатежеспособной, то есть не выполняет свои обязательства перед кредиторами в течение более 90 календарных дней.

2. Факт одновременной реализации двух следующих событий:

- Снижение коэффициента обслуживания долга (DSCR) ниже 1.

- Снижение коэффициента покрытия обязательств по погашению и обслуживанию основного долга за период финансирования (LLCR) ниже 1.

Формулы расчета коэффициентов DSCR и LLCR приведены в таблице 2.

При построении модели использовалась аппроксимация кумулятивных вероятностей нахождения проектов в экспертных рейтингах логистической зависимостью1:

$$
\begin{aligned}
& P_{1,1}=\frac{1}{1+e^{-\left(\vec{a} \times \vec{x}^{T}+b_{1}\right)}} \\
& P_{1, j}=\frac{1}{1+e^{-\left(\vec{a} \times \vec{x}^{T}+b_{j}\right)}} \\
& P_{1, R}=1,(2) \\
& \text { где } P_{1, j} \quad \text { кумулятивная вероятность нахождения инвестиционного проек } \\
& \text { j - п п - порядковый номер соответствующего экспертного рейтинга }{ }^{2}(j=1, \ldots, \mathrm{R}) \text {; } \\
& \vec{x}^{T} \quad \text { - вектор-столбец нормализованных значений риск-факторов, влияющих на экспертный рейтинг } \\
& \vec{a} \quad-\text { вектор-строка регрессионных коэффициентов при нормализованных риск-факторах; } \\
& \begin{array}{l}
- \text { регрессионный коэффициент - свободный член регрессии при оценке кумулятивной вероятности } \\
b_{j}
\end{array}
\end{aligned}
$$

Коэффициенты вектора $\overrightarrow{\boldsymbol{a}}$ и свободные члены регрессии $\boldsymbol{b}_{j}$ находятся на основании максимизации функции правдоподобия:

1. По-другому метод называется Ordinal logistic regression (Карминский, 2015).

2. В данном случае $\mathrm{R}=5$, то есть используется пять экспертных рейтингов, расположенных в порядке улучшения уровня кредитоспособности инвестиционных проектов (рейтинг с порядковым номером 1 - самый негативный, а с порядковым номером 5 - самый позитивный), описание которых приведено в таблице 1. 


$$
L=\sum_{i=1}^{N}\left[Y_{i 1} \times \ln \left(P_{i, 1,1}\right)+\sum_{j=2}^{R}\left[Y_{i j} \times \ln \left(P_{i, 1, j}-P_{i, 1, j-1}\right)\right]\right]
$$

где $Y_{i j}$

- бинарная переменная из множества $\{0 ; 1\}$, фиксирующая факт нахождения і-го инвестиционного проекта в$$
P_{i, 1, j}
$$
экспертном рейтинге с порядковым номером j;

$P_{i, 1, j}$

- кумулятивная вероятность нахождения инвестиционного проекта с порядковым номером $i$ в экспертных рейтингах с порядковыми номерами $1,2, \ldots, j$, полученная с помощью логистической функции (2);

$\mathrm{N}$

- количество инвестиционных проектов в выборке.

В формуле (2) слагаемое $\left(-\vec{a} \times \vec{x}^{T}\right)$ является скоринговым баллом инвестиционного проекта, с учетом того факта, что экспертные рейтинги расположены в порядке возрастания кредитоспособности инвестиционных проектов, то есть чем больше значение скорингового балла ( $-\vec{a} \times \vec{x}^{T}$ ), тем меньше вероятность нахождения инвестиционного проекта в самом консервативном экспертном рейтинге с порядковым номером 1 и выше вероятность нахождения в самом позитивном экспертном рейтинге с порядковым номером 5. Данный факт учитывается при калибровке рейтинговой модели.

Для получения оценки вероятности дефолта на горизонте прогнозирования 1 год с учетом макроэкономического цикла (Жевага и Моргунов, 2015) проводится калибровка скорингового балла $\left(-\vec{a} \times \vec{x}^{T}\right)$ по формуле:

$$
\begin{aligned}
& P D_{1}=\frac{1}{1+e^{\alpha \times\left(-\vec{a} \times \vec{x}^{T}\right)+\beta}},(4) \\
& \text { где } \vec{a} \quad-\text { регрессионные коэффициенты, определенные в формуле (2); }
\end{aligned}
$$

\begin{tabular}{|c|c|c|c|}
\hline Наименование фактора/переменной & Определение фактора & $\begin{array}{l}\text { Обозначение } \\
\text { переменной }\end{array}$ & $\begin{array}{c}\text { Непрерывная / } \\
\text { дискретная }\end{array}$ \\
\hline Коэффициент покрытия & $\begin{array}{c}\text { Отношение суммы кредита к рыночной (или } \\
\text { оценочной) стоимости залога }\end{array}$ & LTV & Непрерывная \\
\hline $\begin{array}{c}\text { Доля собственного участия } \\
\text { бенефициаров }\end{array}$ & $\begin{array}{c}\text { Доля собственного участия бенефициаров в } \\
\text { финансировании проекта }\end{array}$ & $\begin{array}{c}\text { Доля собств. } \\
\text { участия } \\
\text { бенефициаров }\end{array}$ & Непрерывная \\
\hline Внутренняя норма доходности & $\begin{array}{c}\text { Процентная ставка, при дисконтировании } \\
\text { по которой чистый денежный поток по } \\
\text { операционной деятельности с учетом доходов } \\
\text { от участия в капитале третьих лиц равен } \\
\text { инвестиционным затратам } \\
\end{array}$ & IRR & Непрерывная \\
\hline Коэффициент обслуживания долга & $\begin{array}{c}\text { Соотношение суммы чистого денежного } \\
\text { потока на конец реализации проекта и затрат } \\
\text { по обслуживанию долга за период реализации } \\
\text { проекта к затратам по обслуживанию долга за } \\
\text { период реализации проекта }\end{array}$ & DSCR & Непрерывная \\
\hline $\begin{array}{c}\text { Показатель покрытия обязательств } \\
\text { по погашению и обслуживанию } \\
\text { основного долга }\end{array}$ & $\begin{array}{c}\text { Соотношение дисконтированных будущих } \\
\text { поступлений от проекта к суммарным } \\
\text { обязательствам проектных компаний, } \\
\text { подлежащим погашению в течение срока } \\
\text { действия кредита }\end{array}$ & LLCR & Непрерывная \\
\hline Индустриальный фактор & $\begin{array}{c}\text { По группам отраслей: в данной работе } \\
\text { принимает только } 2 \text { значения в соответствии с } \\
\text { табл. } 3\end{array}$ & $\begin{array}{c}\text { Индустриальный } \\
\text { фактор }\end{array}$ & Дискретная \\
\hline
\end{tabular}

При разработке модели рассматривались риск-факторы, приведенные в таблицах 2-4.

Таблиия 2

\section{Перечень риск-факторов}




\begin{tabular}{|c|c|c|c|}
\hline Наименование фактора/переменной & Определение фактора & $\begin{array}{c}\text { Обозначение } \\
\text { переменной }\end{array}$ & $\begin{array}{c}\text { Непрерывная / } \\
\text { дискретная }\end{array}$ \\
\hline Региональный фактор & $\begin{array}{c}\text { По группам регионов: в данной работе } \\
\text { принимает только 2 значения в соответствии с } \\
\text { табл. } 4\end{array}$ & $\begin{array}{c}\text { Региональный } \\
\text { фактор }\end{array}$ & Дискретная \\
\hline
\end{tabular}

Таблица 3

Индустриальный фактор

\begin{tabular}{|c|c|c|}
\hline $\begin{array}{c}\text { Группа } \\
\text { индустиального } \\
\text { фактора }\end{array}$ & Группа отраслей & $\begin{array}{c}\text { Значение } \\
\text { индустриаль-ного } \\
\text { фактора (WOE) }\end{array}$ \\
\hline 1 & Строительство, лесная & $-1,6766$ \\
\hline 2 & $\begin{array}{c}\text { Металлургия и металлообработка, нефтегазовая, пищевая и алкогольная, } \\
\text { сельское хозяйство, торговля, транспорт и связь, энергетика, прочая промыш- } \\
\text { ленность, услуги и прочие отрасли }\end{array}$ & 0,8565 \\
\hline
\end{tabular}

Таблица 4

Региональный фактор

\begin{tabular}{|c|c|c|}
\hline $\begin{array}{c}\text { Группа } \\
\text { регионального } \\
\text { фактора }\end{array}$ & Группа регионов & $\begin{array}{c}\text { Значение } \\
\text { регионального } \\
\text { фактора (WOE) }\end{array}$ \\
\hline 1 & Центральный федеральный округ, Северо-Западный федеральный округ & $-0,5065$ \\
\hline 2 & $\begin{array}{c}\text { Уральский федеральный округ, Приволжский федеральный округ, Дальневосточный } \\
\text { федеральный округ, Сибирский федеральный округ, Южный федеральный округ }\end{array}$ & 0,5082 \\
\hline
\end{tabular}

Выделение групп индустриальных (табл. 3) и региональных (табл. 4) факторов было связано с ограниченностью имеющихся данных и тем, что 62,5\% всех дефолтных проектов (в выборке имелось всего восемь дефолтных проектов) произошли в строительной $(37,5 \%)$ и лесной $(25 \%)$ отраслях, а в региональном разрезе - в Центральном (37,5\%) и Северо-Западном (25\%) федеральных округах; в других отраслях и регионах присутствовало не более одного дефолтного проекта, поэтому индустриальный и региональный факторы были разделены на две группы: с повышенным (группа 1) и стандартным (группа 2) уровнями кредитного риска. Показатель WOE использовался для сопоставления выделенных групп индустриальных и региональных факторов между собой по уровню кредитного риска. Алгоритм определения значений показателя WOE приведен в работе Сиддики (Siddiqi, 2006).

Все используемые риск-факторы (за исключением регионального и индустриального факторов риска) являются относительными. Использование абсолютных факторов риска ${ }^{1}$ (таких, как NPV) при моделировании нецелесообразно, так как они привязаны к определенным этапам экономического цикла и на них значительно влияет инфляция. Абсолютные факторы риска обычно имеют высокую дискриминационную способность при разработке модели, значительно снижающуюся при валидации модели на новых данных из-за изменения структуры этих показателей.

В качестве источников данных использовалась база данных Bureau van Dijk (База данных Руслана) и сайты российских проектных компаний. В данных источниках имелась полная информация для определения только семи неабсолютных показателей (приведенных в табл. 2). При появлении необходимой для расчетов информации целесообразно рассматривать такие факторы риска, как период окупаемости (обычный и дисконтированный) и соотношение периода окупаемости (обычного и дисконтированного) к сроку реализации проекта.

\section{Выборка данных для построения модели и временной горизонт данных}

Выборка инвестиционных проектов (обучающая выборка²) включает российские проекты, реализация которых началась в 2007-2013 гг. Ее описательные статистики приведены в Прило-

1. Которые принимают абсолютные значения.

2. Обучающей называют выборку, на которой производится разработка модели. 
жении к статье (далее - Приложение). Общее количество инвестиционных проектов в выборке - 85. Структуры выборки по отраслям и регионам приведены на рисунках 1-2:
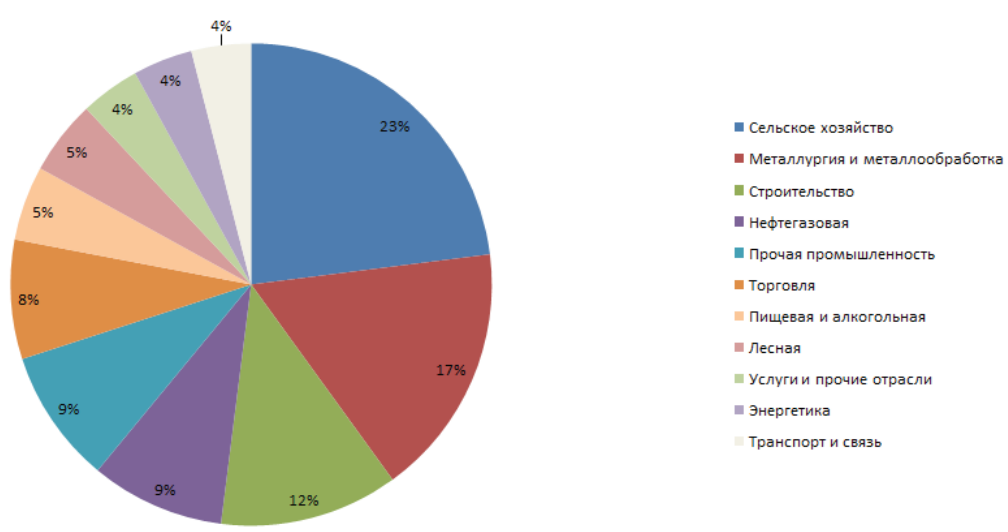

Рисунок 1. Структура выборки по отраслям
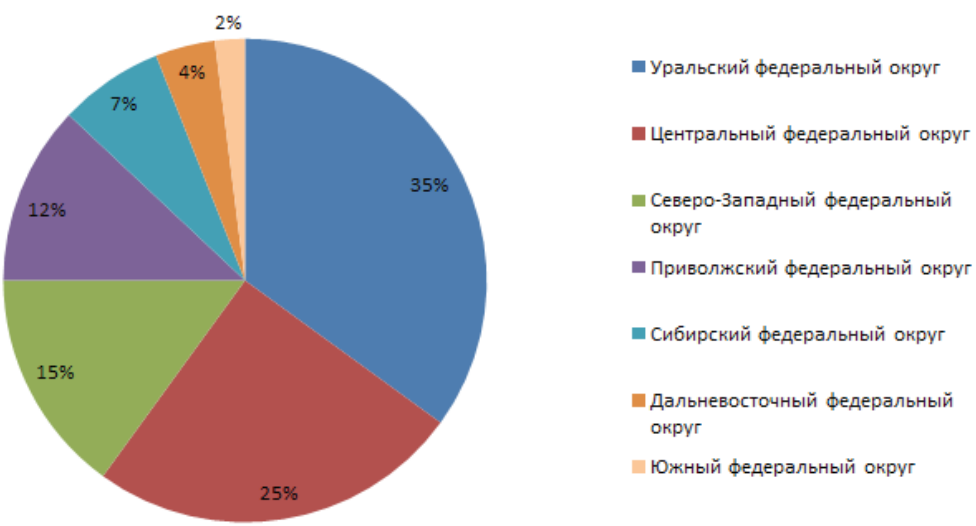

Южный федеральный округ

Рисунок 2. Структура выборки по регионам

Распределение выборки по экспертным рейтингам приведено в таблице 5.

Распределение экспертных рейтингов

\begin{tabular}{|c|c|}
\hline $\begin{array}{c}\text { Экспертный } \\
\text { рейтинг }\end{array}$ & Количество значений в выборке \\
\hline 1 & 8 \\
\hline 2 & 25 \\
\hline 3 & 25 \\
\hline 4 & 15 \\
\hline 5 & 12 \\
\hline Итого & 85 \\
\hline
\end{tabular}

\section{Преобразование данных}

Для снижения влияния выбросов и увеличения дискриминационной способности и устойчивости регрессионных коэффициентов модели в отношении отдельных непрерывных рискфакторов была произведено преобразование исходных данных, называемое логистической трансформацией (Карминский и Фалько, 2013). Параметры логистической трансформации представлены в таблице 6.

Таблииа 6

Параметры логистической трансформации

\begin{tabular}{|c|c|c|}
\hline Риск-фактор & Median & Slope \\
\hline LTV & 0,85 & 0,77 \\
\hline
\end{tabular}




\begin{tabular}{|c|c|c|}
\hline Риск-фактор & Median & Slope \\
\hline Доля собств. участия бенефициаров & 0,28 & 10,68 \\
\hline IRR & 0,19 & 8,52 \\
\hline DSCR & 1,48 & 0,42 \\
\hline LLCR & 1,32 & 0,30 \\
\hline
\end{tabular}

Для обеспечения сопоставимости значений факторов риска на одной шкале (в стандартных отклонениях) в отношении трансформированных значений непрерывных риск-факторов, перечисленных табл. 6, и дискретных риск-факторов «Индустриальный фактор» и «Региональный фактор» была произведена нормализация их значений (Карминский, Фалько, 2013). Параметры нормализации приведены в табл. 7:

Таблица 7

Параметры нормализации

\begin{tabular}{|c|c|c|}
\hline Риск-фактор & Mean & 0,14 \\
\hline LTV & 0,53 & 0,28 \\
\hline Доля собств. участия бенефициаров & 0,47 & 0,18 \\
\hline IRR & 0,55 & 0,14 \\
\hline DSCR & 0,55 & 0,13 \\
\hline LLCR & 0,53 & 0,95 \\
\hline Индустриальный фактор & 0,44 & 0,50 \\
\hline
\end{tabular}

Анализ выборки и построение модели

Для всех нормализованных риск-факторов был проведен однофакторный анализ (Siddiqi, 2006; Карминский, 2015; Моргунов и Жевага, 2015). Цель однофакторного анализа - оценка влияния нормализованных значений указанных риск-факторов на ранжирование инвестиционных проектов на основании однофакторного показателя AR (Sommer's D) (Allen, 2003; Jorion, 2007; Карминский и Фалько, 2013; Лобанов и Чугунов, 2009).

Коэффициент AR (Sommer's D) показывает ранговую корреляцию (взаимосвязь) между рискфакторами (или скоринговыми баллами для многофакторных моделей) и экспертными рейтингами и рассчитывается по формуле:

$S D=\frac{N_{C}-N_{D}}{N_{0}-N_{1}}$, где $\mathrm{SD}$

- значение показателя $A R$ (Sommer's D);

- количество согласованных пар между значениями риск-фактора (скорингового балла) и экспертны-

$N_{C} \quad$ - количество несогласованных пар между значениями риск-фактора (скорингового балла) и эксперт-

$N_{D}$

$N_{0}$ ными рейтингами;

- суммарное количество перестановок в выборке (для выборки размерности $N$ :

$$
\left.N_{0}=\frac{N \times(N-1)}{2}\right) ;
$$

$N_{1} \quad-$ суммарное количество перестановок повторяющихся значений экспертных рейтингов в выборке (

$$
N_{1}=\sum_{i}^{L}\left(\frac{t_{i} \times\left(t_{i}-1\right)}{2}\right),
$$

где $t_{i}$ - количество повторяющихся значений для экспертного рейтинга с порядковым номером $i$, а $L$ - общее количество экспертных рейтингов (в нашем случае $L=5$ ).

Оценка дискриминационной способности риск-факторов и моделей производится (Siddiqi, 2006) по уровню коэффициента Sommer's D по аналогии с коэффициентом Джини от уровня $[0 ; 0,2)$ как неудовлетворительная через хорошую $[0,4 ; 0,6)$ до отличной для значений от 0,8 и выше. 
Результаты и графическая интерпретация однофакторного анализа приведены на рисунке 3.

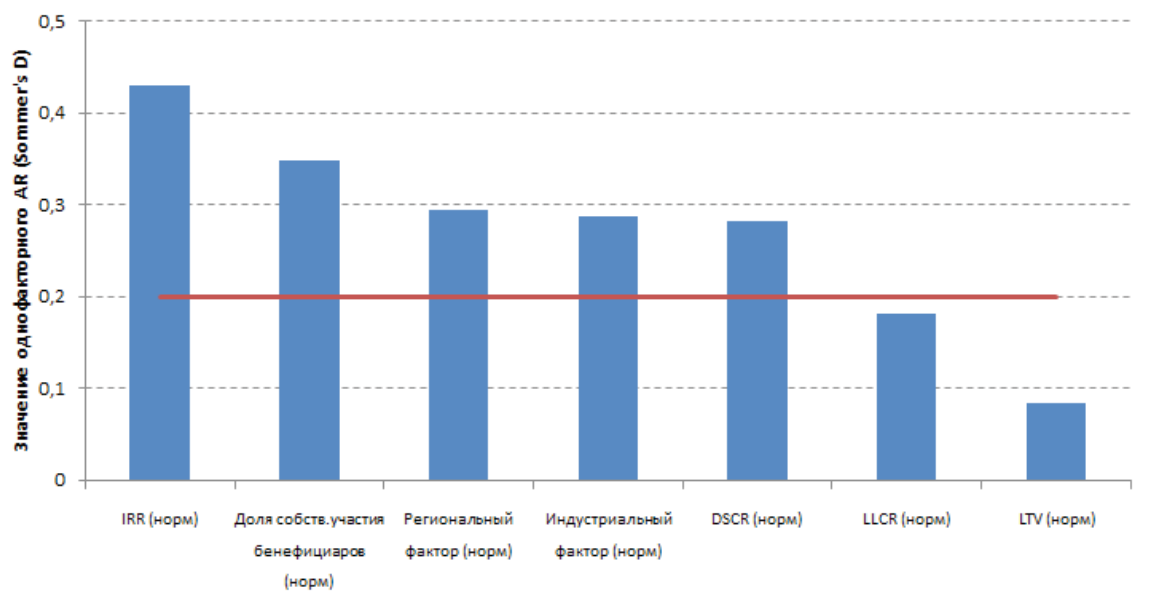

Рисунок 3. Результаты и графическая интерпретация однофакторного анализа

В отношении нормализованных риск-факторов был проведен тест на соответствие знаков регрессионных коэффициентов, заключавшийся в проверке соответствия модельной логики ранжирования инвестиционных проектов с использованием отдельных риск-факторов экономической логике. Сформированные гипотезы по экономической логике факторов риска и сами результаты теста приведены в таблице 7.

Таблица 7

Соответствия модельной логики и экономической логики (гипотезы) риск-факторов

\begin{tabular}{|c|c|c|c|}
\hline № & Риск-фактор & Гипотеза & $\begin{array}{c}\text { Модельная логика } \\
\text { соответствует } \\
\text { экономической (гипотезе) }\end{array}$ \\
\hline 1 & LLCR $_{\text {Norm }}$ & $\begin{array}{c}\text { По мере увеличения дисконтированных будущих поступлений } \\
\text { от проекта и уменьшения суммарных обязательств проектных } \\
\text { компаний, подлежащих погашению в течение срока действия кредита, } \\
\text { ожидается снижение уровня принимаемых кредитных рисков на } \\
\text { инвестиционный проект }\end{array}$ & Да \\
\hline 2 & $\begin{array}{c}\text { Индустриальный } \\
\text { фактор }_{\text {Norm }}\end{array}$ & $\begin{array}{c}\text { Для отраслей промышленности «Строительство» и «Лесная» } \\
\text { (наименьшее значение WOE) уровень принимаемого кредитного риска } \\
\text { на проект ожидается выше, чем для остальных отраслей в силу боль- } \\
\text { шей волатильности стоимости продукции в этих отраслях и большей } \\
\text { их подверженности влиянию кризисов }\end{array}$ & Да \\
\hline 3 & $\mathrm{IRR}_{\text {Norm }}$ & $\begin{array}{c}\text { По мере увеличения внутренней нормы доходности инвестиционного } \\
\text { проекта ожидается уменьшение уровня принимаемого кредитного } \\
\text { риска на инвестиционный проект }\end{array}$ & Да \\
\hline 4 & $\mathrm{DSCR}_{\text {Norm }}$ & $\begin{array}{c}\text { Можно ожидать снижения уровня принимаемых кредитных рисков по } \\
\text { мере увеличения чистого денежного потока на конец реализации про- } \\
\text { екта и снижения затрат по обслуживанию долга за период реализации } \\
\text { проекта }\end{array}$ & Да \\
\hline 5 & $\begin{array}{c}\text { Региональный } \\
\text { фактор }_{\text {Norm }}\end{array}$ & $\begin{array}{c}\text { Для Центрального и Северо-Западного федеральных округов, куда } \\
\text { входят и две столицы России, ожидаемый уровень принимаемого } \\
\text { кредитного риска на проект выше, чем для остальных регионов в силу } \\
\text { большей волатильности региональных условий }\end{array}$ & Да \\
\hline 6 & $\begin{array}{l}\text { Доля собственного } \\
\text { участия } \\
\text { бенефициаров }_{\text {Norm }}\end{array}$ & $\begin{array}{c}\text { По мере уменьшения доли участия бенефициаров в финансировании } \\
\text { проекта увеличивается доля финансирования проекта кредитной } \\
\text { организацией. При этом усиливается контроль использования } \\
\text { средств на реализацию проекта кредитной организацией, а также } \\
\text { планов и результатов реализации проекта. Эти обстоятельства } \\
\text { приводят к повышению вероятности успешной реализации проекта } \\
\text { и соответственно к снижению кредитных рисков. Можно ожидать } \\
\text { U-образной зависимости, но в силу ограниченности выборки эту } \\
\text { гипотезу сложно проверить }\end{array}$ & Да \\
\hline 7 & $\mathrm{LTV}_{\text {Norm }}$ & $\begin{array}{c}\text { Можно ожидать увеличения уровня принимаемых кредитных рисков } \\
\text { по мере увеличения суммы кредита и снижения рыночной (или оце- } \\
\text { ночной) стоимости залога }\end{array}$ & Нет \\
\hline
\end{tabular}


Модельная логика ранжирования проектов для каждого из риск-факторов совпадает с экономической логикой (гипотезой), за исключением риск-фактора LTVNorm, поэтому оценка дискриминационной способности имеет смысл для всех риск-факторов, за исключением LTVNorm ${ }^{1}$, который исключается из рассмотрения.

Риск-фактор LLCRNorm обладает низкой дискриминационной способностью (значение однофакторного коэффициента AR (Sommer's D) составило менее 20\%) и также исключается из рассмотрения как статистически незначимый, слабо влияющий на экспертное ранжирование инвестиционных проектов.

В отношении оставшихся риск-факторов был проведен корреляционный анализ (Карминский и Костров, 2013), целью которого являлось выявление фактов наличия линейной зависимости. В результате проведенного анализа случаев линейной зависимости между какими-либо из оставшихся риск-факторов (коэффициент корреляции Пирсона более $+/-0,60$ ) обнаружено не было.

На основании оставшихся пяти риск-факторов было разработано 26 моделей с учетом всех возможных комбинаций риск-факторов с вхождением от двух до пяти факторов в модель: 10 двухфакторных моделей $\left(\mathrm{C}^{2}{ }_{5}=10\right)^{3}, 10$ трехфакторных моделей $\left(\mathrm{C}^{3}{ }_{5}=10\right)$, пяти четырехфакторных моделей $\left(\mathrm{C}_{5}^{4}=10\right)$ и одной пятифакторной модели $\left(\mathrm{C}_{5}^{5}=10\right)$. Из этих моделей были отобраны две модели с наиболее высокими дискриминационными способностями. Дискриминационные способности моделей оценивались на основании многофакторного показателя AR (Sommer’s D) ${ }^{4}$. Выбранные модели приведены в таблице 8.

Таблица 8

Модели с наиболее высокой дискриминационной способностью

\begin{tabular}{|c|c|c|c|c|c|c|}
\hline $\begin{array}{c}\text { Номер мо- } \\
\text { дели }\end{array}$ & $\begin{array}{c}\text { Риск- } \\
\text { фактор } 1\end{array}$ & $\begin{array}{c}\text { Риск-фактор } \\
2\end{array}$ & Риск-фактор 3 & Риск-фактор 4 & Риск-фактор 5 & $\begin{array}{c}\text { AR } \\
\text { (Sommer's D) }\end{array}$ \\
\hline Модель 1 & $\begin{array}{c}\text { Доля собств. } \\
\text { участия } \\
\text { бенефициаров }_{\text {Norm }}\end{array}$ & $\mathrm{IRR}_{\text {Norm }}$ & $\mathrm{DSCR}_{\text {Norm }}$ & $\begin{array}{c}\text { Индустриальный } \\
\text { фактор }_{\text {Norm }}\end{array}$ & $\begin{array}{c}\text { Региональ ный } \\
\text { фактор }_{\text {Norm }}\end{array}$ & $79,82 \%$ \\
\hline Модель 2 & $\begin{array}{c}\text { Доля собств. } \\
\text { участия } \\
\text { бенефициаров }_{\mathrm{Norm}}\end{array}$ & $\mathrm{IRR}_{\text {Norm }}$ & $\begin{array}{c}\text { Индустриальный } \\
\text { фактор }_{\text {Norm }}\end{array}$ & $\begin{array}{c}\text { Региональ ный } \\
\text { фактор }_{\text {Norm }}\end{array}$ & & $79,82 \%$ \\
\hline
\end{tabular}

Характеристики моделей из таблицы 8 приведены в Приложении.

В отношении обеих моделей был проведен тест на соответствие знаков регрессионных коэффициентов (Карминский, 2015). Экономическая логика по отдельным факторам риска приводится в таблице 7. В моделях 1 и 2 знаки регрессионных коэффициентов соответствуют экономической логике.

Также в отношении каждой модели был проведен эконометрический тест на устойчивость (t-критерий Стьюдента) (Карминский и Фалько, 2013) на доверительном уровне 85\%. Результаты теста приведены в таблице 9.

Таблица 9

Результаты теста на устойчивость, \%

\begin{tabular}{|c|c|c|}
\hline Переменная & p-value (модель 1) & p-value (модель 2) \\
\hline Доля собств. участия бенефициаров $_{\text {Norm }}$ & $<0,0001$ & $<0,0001$ \\
\hline IRR $_{\text {Norm }}$ & $<0,0001$ & $<0,0001$ \\
\hline DSCR $_{\text {Norm }}$ & 47,98 & - \\
\hline Индустриальный фактор $_{\text {Norm }}$ & $<0,0001$ & $<0,0001$ \\
\hline
\end{tabular}

1. Риск-фактор LTVNorm исключается из рассмотрения и по низкой дискриминационной способности (рис. 3).

2. Корреляционная матрица приведена в Приложении.

3. $C_{n}^{k}-$ количество сочетаний из n по k элементов.

4. Показатель рассчитывается по аналогии с однофакторным AR (Sommer's D), но только не для отдельных показателей, а для моделей в целом. 


\begin{tabular}{|c|c|c|}
\hline Переменная & p-value (модель 1) & p-value (модель 2) \\
\hline Региональный фактор \\
Norm
\end{tabular}

В отношении модели 1 тест на устойчивость не выполнен в отношении риск-фактора DSCRNorm (в данной модели он имеет низкую статистическую значимость). Таким образом, данный фактор риска целесообразно исключить. Исключение риск-фактора $\mathrm{DSCR}_{\mathrm{Norm}}$ приводит к модели 2. В отношении модели 2 тест на устойчивость выполнен для всех рискфакторов. Принимая во внимание результаты теста на устойчивость, а также с учетом одинаковых дискриминационных способностей моделей модель 2 признана в качестве оптимальной и используется в дальнейшем анализе.

В модели 2 дополнительно исследовались нелинейные зависимости в отношении непрерывных риск-факторов «Доля собств. участия бенефициаров» и IRR. Использовались

следующие нелинейные преобразования $\left(^{*}\right)^{1}$ : Доля соб. участия бен. ${ }^{*}=\ln (1+\mid$ Доля соб.участия бен.|) х $\operatorname{sign}\left(\right.$ Доля соб. участия бен.) и $I R R^{*}=\ln (1+|\operatorname{IRR}|) \times \operatorname{sign}(\operatorname{IRR})$.

После проведения трансформации и нормализации соответствующих нелинейных рискфакторов, параметры которых приведены в таблице 10, были разработаны еще три модели, отличающиеся от модели 2 наличием хотя бы одного из нелинейных факторов риска. Перечень данных моделей представлен в таблице 11.

Таблица 10

Параметры трансформации и нормализации для нелинейных риск-факторов

\begin{tabular}{|c|c|c|c|c|}
\hline Риск-фактор & Median & Slope & Mean & StdDev \\
\hline Доля собств. участия бенефициаров* & 0,25 & 15,10 & 0,46 & 0,29 \\
\hline IRR* $^{*}$ & 0,18 & 11,59 & 0,55 & 0,19 \\
\hline
\end{tabular}

Таблица 11

Перечень моделей с нелинейными факторами риска

\begin{tabular}{|c|c|c|c|c|c|}
\hline Номер модели & $\begin{array}{c}\text { Риск- } \\
\text { фактор } 1\end{array}$ & Риск-фактор 2 & Риск-фактор 3 & Риск-фактор 4 & $\begin{array}{c}A R \\
\text { (Sommer's D), \% }\end{array}$ \\
\hline Модель 2.1 & $\begin{array}{l}\text { Доля собств. участия } \\
\text { бенефициаров }{ }_{\text {Norm }}\end{array}$ & $\mathrm{IRR}^{*}{ }_{\text {Norm }}$ & $\begin{array}{l}\text { Индустриаль- } \\
\text { ный фактор }_{\text {Norm }}\end{array}$ & $\begin{array}{c}\text { Региональный } \\
\text { фактор }_{\text {Norm }}\end{array}$ & 80,11 \\
\hline Модель 2.2 & $\begin{array}{l}\text { Доля собств. участия } \\
\text { бенефициаров }_{\text {Norm }}\end{array}$ & $\mathrm{IRR}^{*}{ }_{\text {Norm }}$ & $\begin{array}{l}\text { Индустриаль- } \\
\text { ный фактор } \\
\text { Norm }\end{array}$ & $\begin{array}{c}\text { Региональный } \\
\text { фактор } \\
\text { Norm }\end{array}$ & 79,96 \\
\hline Модель 2.3 & $\begin{array}{l}\text { Доля собств. участия } \\
\text { бенефициаров }{ }_{\text {Norm }}\end{array}$ & $\mathrm{IRR}_{\text {Norm }}$ & $\begin{array}{l}\text { Индустриаль- } \\
\text { ный фактор } \\
\text { Norm }\end{array}$ & $\begin{array}{c}\text { Региональный } \\
\text { фактор } \\
\text { Norm }\end{array}$ & 79,59 \\
\hline
\end{tabular}

С учетом большее высокой дискриминационной способности модель 2.1 была выбрана в качестве оптимальной (характеристики моделей из табл. 11 приведены в Приложении). Тест на устойчивость для модели 2.1 выполнен на доверительном уровне $85 \%$, а корреляционные зависимости отсутствуют (корреляционная матрица риск-факторов модели 2.1 приведена в Приложении). Дискриминационная способность оптимальной модели - отличная, так как AR $($ Sommer's D) $=80,11 \%(>80 \%)$.

Оптимальная модель позволяет получить кумулятивную вероятность нахождения инвестиционного проекта в экспертных рейтингах с порядковыми номерами $1,2, \ldots$, j по формуле (6):

$$
P_{1, j}=\frac{1}{1+e^{-1,3742 \times \text { Доля собств. участ. бен. }{ }^{*}{ }_{\text {Norm }}+1,6121 \times I R R^{*}{ }_{\text {Norm }}+1,6268 \times \text { Инд. } . \text { фактор }} \text { Norm }+1,2319 \times \text { Pez. }_{\text {paктор }} \text { Norm }+ \text { Int }_{j}}
$$

где свободные члены регрессии Intj при оценке кумулятивной вероятности нахождения инвестиционного проекта в экспертных рейтингах с порядковыми номерами 1, 2, 3, 4 равны соответственно: Int1 = 4,8329, Int2 = 1,2418, Int3 = -2,0858, Int4 = -3,9699.

1. * - обозначение факта преобразования риск-факторов «Доля собств. участия бенефициаров» и IRR нелинейными зависимостями с использованием натурального логарифма $(\ln )$ и функции сигнум $(\operatorname{sign}): \operatorname{sign}(\mathrm{x})=1$ при $\mathrm{x}$ $>0 ; \operatorname{sign}(\mathrm{x})=0$ при $\mathrm{x}=0 ; \operatorname{sign}(\mathrm{x})=-1$ при $\mathrm{x}<0$. 
Нормированные веса риск-факторов для оптимальной модели представлены в таблице 12.

Таблицьа 12

Нормированный вес риск-факторов в оптимальной модели, \%

\begin{tabular}{|c|c|c|c|}
\hline $\begin{array}{c}\text { Доля собств. участия } \\
\text { бенефициаров }{ }_{\text {Norm }}\end{array}$ & IRR $_{\text {Norm }}^{*}$ & $\begin{array}{c}\text { Индустриальный } \\
\text { фактор }\end{array}$ & $\begin{array}{c}\text { Региональный } \\
\text { фактор }_{\text {Norm }}\end{array}$ \\
\hline $\mathbf{2 3}$ & $\mathbf{2 8}$ & $\mathbf{2 8}$ & $\mathbf{2 1}$ \\
\hline
\end{tabular}

Так образом, по сравнению с оптимальной моделью бинарного выбора, где наибольшим весом обладал риск-фактор IRR, вес в оптимальной модели множественного выбора распределен более равномерно.

Для оценки вероятности дефолта инвестиционных проектов в отношении модели (6) была произведена калибровка модели (на данных по недефолтным проектам по состоянию на 01.01.2014), позволяющая учесть макроэкономическую конъюнктуру рынка и требования базельских соглашений о необходимости расчета вероятности дефолта на годовом горизонте прогнозирования. При калибровке модели использовались следующие основные допущения:

- Калибровка модели осуществлялась с использованием прогнозной вероятности дефолта на следующий год (концепция Point-in-Time), которая принимает значение 12,50\% с учетом принципа консервативности и сопоставимости с кризисным 2009 г.

- Оценки вероятности дефолта не должны быть меньше значения 0,25\% (Власов и Помазанов, 2008), которое соответствует годовой вероятности дефолта рейтинга S\&P Российской Федерации по состоянию на 01.01.2014 (рейтинг - ВВВ).

Применяя указанные допущения, на основании формулы (6) (без учета свободных членов регрессии) была получена оценка годовой вероятности дефолта инвестиционных проектов по следующей формуле (7):

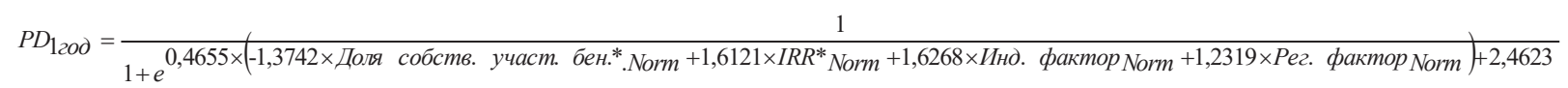

C учетом формулы (7) на основании расчета K-S-статистики (Карминский и Фалько, 2013) был разработан алгоритм принятия решения о целесообразности участия кредитной организации в инвестиционном проекте.

На рисунке 4 приведена графическая интерпретация полученной K-S-статистики:

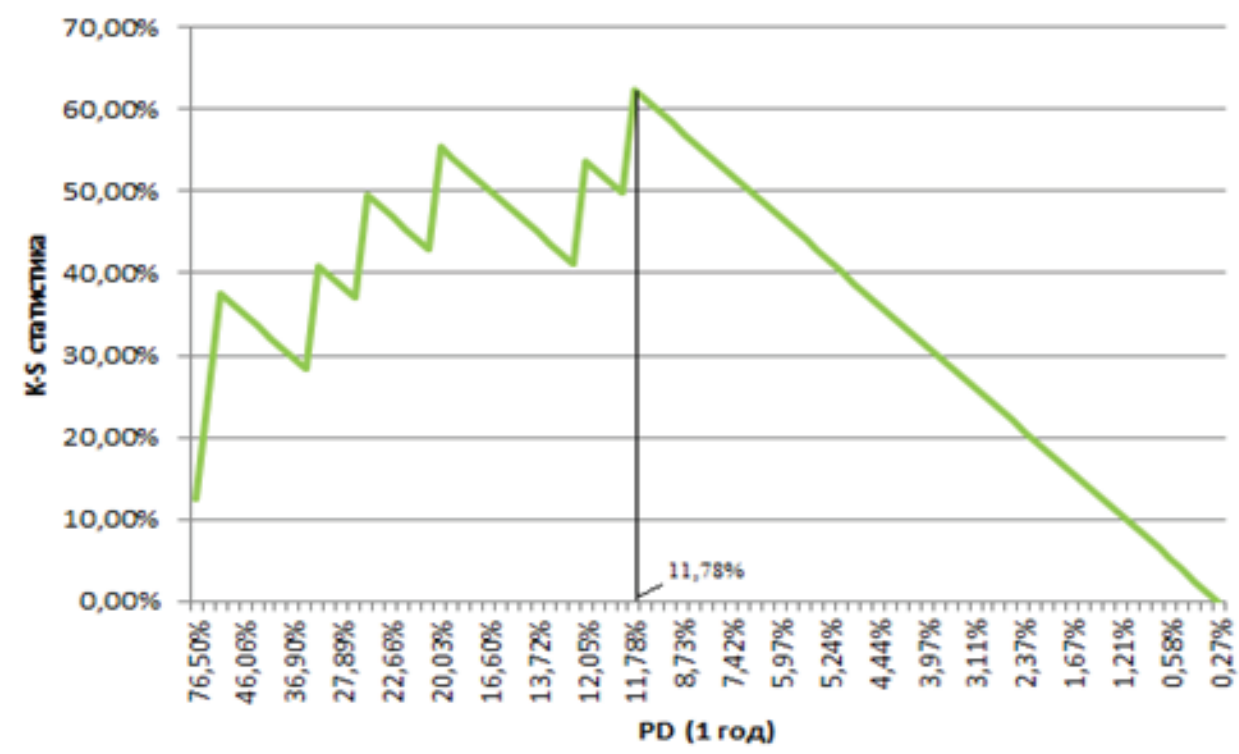

Рисунок 4. Графическая интерпретация K-S-статистики

Таким образом, принятие решения о целесообразности участия кредитной организации в инвестиционном проекте может осуществляться согласно алгоритму, представленному в таблице 14. 
Алгоритм принятия решения об участии в инвестиционном проекте

\begin{tabular}{|c|c|}
\hline PD $_{\text {Ігод }}$ по инвестиционному проекту & Решение об участии в инвестиционном проекте \\
\hline $\mathrm{PD}_{\text {1год }} \geq 11,78 \%$ & Рекомендуется отказаться от участия в инвестиционном проекте \\
\hline $\mathrm{PD}_{1 \text { год }}<11,78 \%$ & Рекомендуется принять участие в инвестиционном проекте \\
\hline
\end{tabular}

Далее в статье будут представлены результаты валидации модели множественного выбора и модели бинарного выбора (Карминский, Моргунов и Богданов, 2015).

\section{Валидация моделей оценки вероятности дефолта сделок проектного финансирования}

По результатам наблюдений за российскими инвестиционными проектами (по действующим на начало 2014 г. проектам, по которым на тот момент отсутствовали признаки дефолта), за 2014 г. была сформирована выборка для валидации моделей бинарного и множественного выбора (валидационная выборка), которая имела следующие характеристики:

- $\quad$ Количество инвестиционных проектов - 77.

- Количество дефолтных инвестиционных проектов - 6 .

- Частота дефолтных проектов - 7,79\%.

Таким образом, выборка включала перечень всех факторов риска, приведенных в таблице 2, значения которых были определены по состоянию на 01.01.2014. Структура валидационной выборки по отраслям и регионам приведена на графиках:
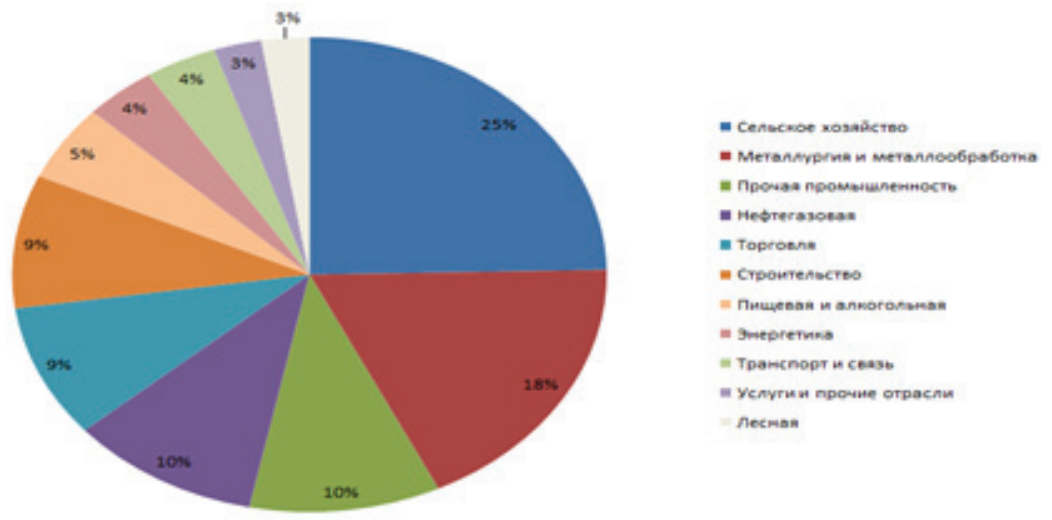

Рисунок 5. Структура валидационной выборки по отраслям
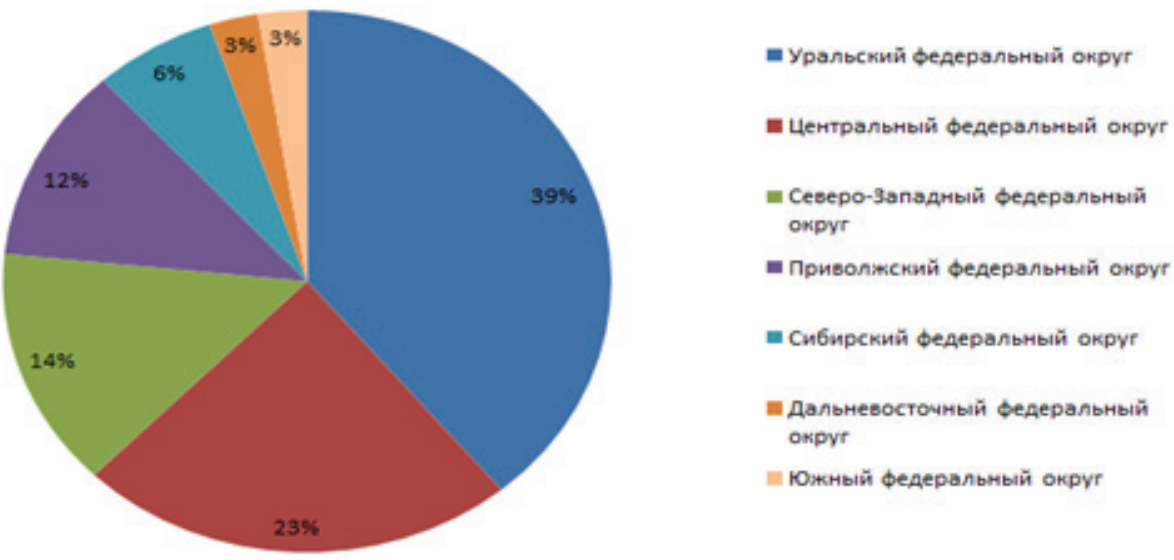

= Уральский федеральный округ

- Lентральный федеральный округ

- Северо-Западмый федеральный oxpyr

- Приволжский федеральный округ

= сибирский федеральный округ

= Дальневосточный федеральный okpyr

шюжный федеральжый округ

Рисунок 6. Структура валидационной выборки по регионам

Структуры выборок как для разработки, так и для валидации моделей оказались сопоставимыми (это следует из сопоставления рис. 1 , рис. 2 с рис. 5 , рис. 6).

По отношению к наблюдениям выборки были применены трансформация и нормализация, при осуществлении которых были использованы коэффициенты из таблиц 6, 7 и 10. 
Целями и задачами (этапами) проводимой валидации являлись:

- Сопоставление дискриминационных способностей и отдельных характеристик моделей бинарного ${ }^{1}$ и множественного выбора (многофакторный анализ).

- Оценка дискриминационных способностей риск-факторов (однофакторный анализ) и корреляционный анализ риск-факторов.

- Формирование рекомендаций по результатам валидации модели.

Изначально в качестве целей и задач валидации дополнительно рассматривалась задача оценки предсказательной способности модели (с использованием хи-квадрат-теста). Однако с учетом наличия в выборке всего шести дефолтных инвестиционных проектов оценка предсказательной способности модели оказалась невозможна.

В статье будут приведены основные результаты каждого из обозначенных этапов.

Сопоставление дискриминационных способностей и отдельных характеристик моделей бинарного и множественного выбора (многофакторныий анализ)

Результаты сопоставления дискриминационных способностей моделей (на основании коэффициента Джини) и некоторых их отдельных характеристик представлены в таблице 15.

Таблица 15

Результаты сопоставимости моделей бинарного и множественного выбора

\begin{tabular}{|c|c|c|}
\hline Статистика & Модель множественного выбора & Модель бинарного выбора \\
\hline AR (Gini) & $66,67 \%$ & $70,89 \%$ \\
\hline AUC (Площадь под ROC-кривой) & $83,33 \%$ & $85,45 \%$ \\
\hline LogL & $-16,82$ & $-15,36$ \\
\hline Pseudo-R2 & $20,18 \%$ & $27,12 \%$ \\
\hline
\end{tabular}

Из результатов сопоставления моделей видно, что модель бинарного выбора показала более точные результаты на валидационной выборке (хотя оценки точности сопоставимы).

Сопоставимость дискриминационных способностей моделей приведена на рисунке 7:

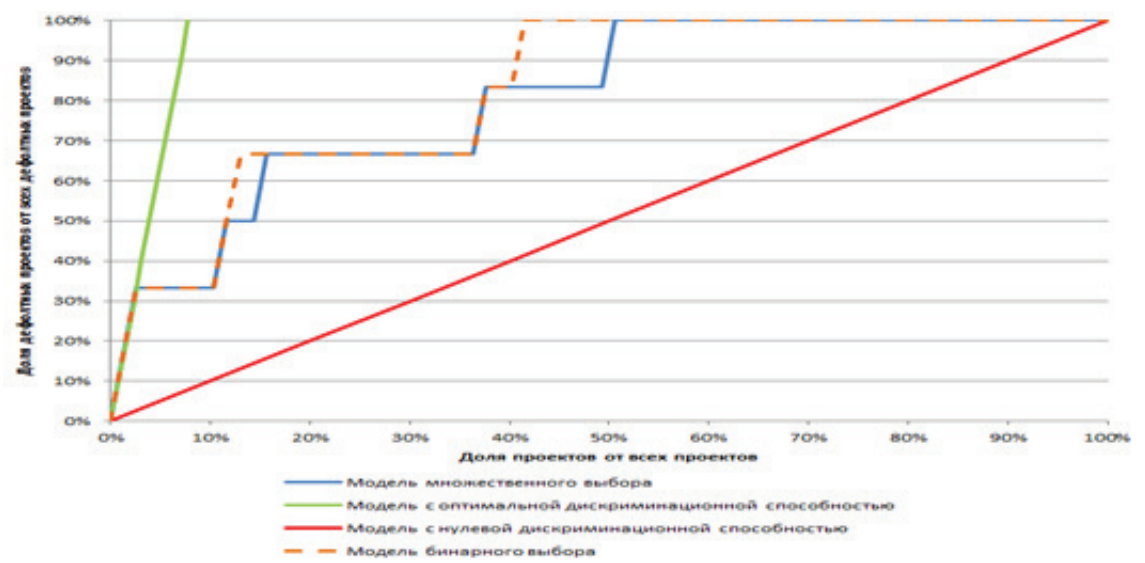

Рисунок 7. Сопоставимость моделей бинарного и множественного выбора

Таким образом, дискриминационные способности моделей множественного и бинарного выбора по результатам валидации являются очень хорошими, но модель бинарного выбора оказалась точнее. Поэтому ее можно считать оптимальной в рамках исследования.

Экономический смысл данного результата - риск-фактор IRR оказывает наиболее сильное влияние на кредитоспособность инвестиционного проекта (так как точность модели множественного выбора по результатам валидации ниже, так как показателю IRR придается меньший вес). Но необходимо понимать, что данная гипотеза сформирована на выборке малого объема и при увеличении объема выборки вполне может быть отклонена, а в качестве оптимальной модели выбрана модель множественного выбора.

1. В статье Карминского и соавторов (Карминский, Моргунов и Богданов, 2015) модель бинарного выбора представлена формулой (11). 
Оценка дискриминационных способностей отдельных факторов риска приведена на рисунке 81.

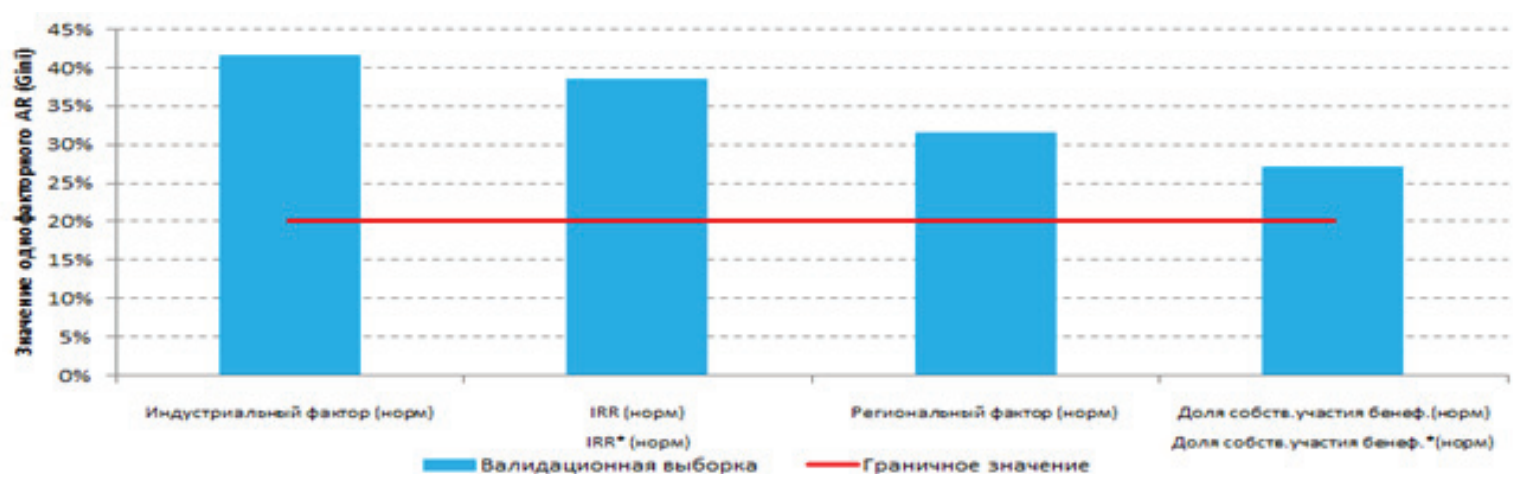

Рисунок 8. Результать однофакторного анализа при валидаџии моделей

Из рисунка 8 следует, что все входящие в модели бинарного и множественного выбора факторы риска являются статистически значимыми. Таким образом, исключение из моделей отдельных факторов риска представляется нецелесообразным.

Риск-фактор «Индустриальный фактор» является самым значимым по результатам однофакторного анализа, однако при работе в связке лучше работает риск-фактор IRR (второй по значимости по результатам однофакторного анализа), так как является непрерывным фактором риска (в отличие от «Индустриального фактора»).

По результатам корреляционного анализа риск-факторов ${ }^{2}$ на валидационной выборке, входящих в модели бинарного и множественного выбора, линейных зависимостей (коэффициент корреляции Пирсона > 0,6) обнаружено не было.

По результатам сопоставления моделей бинарного и множественного выбора было приято решение считать модель бинарного выбора оптимальной в рамках данного исследования из-за более высокой точности.

\section{Формирование рекомендаций по результатам валидации модели}

По результатам проведенной валидации были выработаны следующие рекомендации по улучшению качества разработанных моделей:

- При появлении соответствующей информации с целью улучшения качества разработанных моделей целесообразно рассматривать такие факторы риска, как период окупаемости (обычный и дисконтированный) и соотношение периода окупаемости (обычного и дисконтированного) к сроку реализации проекта.

- При появлении соответствующей информации целесообразно разработать экспертную модель, включающую в себя качественные критерии оценки по проектам, входящим в выборку и получить оптимальную по точности совокупную модель, включающую в себя как качественные, так и количественные факторы риска.

- При появлении соответствующей информации целесообразно учесть возможные дополнительные (редкие) факторы риска, влияющие на корректировки (снижение) оценок кредитоспособности отдельных проектов.

- $\quad$ При появлении информации о валовой прибыли с недефолтных проектов и потерях с дефолтных проектов рассчитать балл отсечения исходя из максимизации средней вало-

1. Красная линия - минимальное пороговое значение для коэффициента Джини, которое позволяет считать фактор риска статистически значимым.

2. В качестве коэффициентов парной корреляции рассматривались коэффициенты корреляции Пирсона. Результаты корреляционного анализа на валидационной выборке в отношении моделей бинарного и множественного выбора приведены в Приложении. 
вой прибыли на инвестиционный проект и скорректировать алгоритм принятия решения о целесообразности участия в инвестиционном проекте.

\section{Заключение}

Новизна исследования заключается в адаптации подхода к построению моделей на основе множественного выбора для российских инвестиционных проектов и в сопоставлении между собой подходов на основе бинарного и множественного выбора с помощью классических валидационных характеристик и критериев.

Разработка методологии оценки кредитного риска сделок проектного финансирования, представленная в статье, включает в себя регрессионные модели множественного выбора, основанные на экспертном ранжировании инвестиционных проектов. Выборка инвестиционных проектов включала в себя около 100 российских инвестиционных проектов, использовавшихся ранее при разработке модели бинарного выбора (Карминский, Моргунов и Богданов, 2015). Полученная модель является альтернативной модели бинарного выбора и имеет высокое качество на обучающей выборке со значением коэффициента Sommer's D, равным 80,11\%. Наибольшим нормированным весом обладают риск-факторы IRR и «Индустриальный фактор» (порядка 28\%). Веса риск-факторов «Доля собств. участия бенефициаров» и «Региональный фактор» составляют соответственно $23 \%$ и $21 \%$. Таким образом, вес риск-факторов в полученной модели распределен более равномерно, чем в модели бинарного выбора (Карминский, Моргунов и Богданов, 2015), в которой выделялся риск-фактор IRR с весом порядка 42\%. Тест на устойчивость (t-критерий Стьюдента) в оптимальной модели множественного выбора был выполнен в отношении всех показателей. Для возможности оценки вероятности дефолта на годовом горизонте прогнозирования (Basel, 2011) по аналогии с моделью бинарного выбора (Карминский, Моргунов и Богданов, 2015) была произведена дополнительная калибровка модели множественного выбора с учетом консервативности прогнозируемой годовой вероятности дефолта $(12,50 \%)$. На основании статистики Колмогорова-Смирнова получен алгоритм принятия решения об участии в инвестиционном проекте на основании разработанной модели множественного выбора.

По результатам наблюдений за российскими инвестиционными проектами (по действующим на начало 2014 г. проектам, по которым на тот момент отсутствовали признаки дефолта) за 2014 г. была сформирована выборка для валидации моделей бинарного и множественного выбора, эмпирическая частота дефолтных проектов в которой составила 7,79\%. По результатам валидации более высокую точность продемонстрировала модель бинарного выбора: коэффициент Джини для модели бинарного выбора составил 70,89\%, а для модели множественного выбора - 66,67\%, которую и предложено считать оптимальной в рамках данного исследования. Таким образом, сформирована гипотеза о том, что риск-фактор IRR в моделях оценки кредитоспособности инвестиционных проектов наиболее значим. Однако, при увеличении объема выборки полученная гипотеза может быть опровергнута, а в качестве оптимальной выбрана модель множественного выбора.

Подводя итог, отмечу, что по результатам исследования можно сделать выводы о возможности применения методов бинарного и множественного выбора при оценке кредитоспособности инвестиционных проектов и сильном влиянии риск-фактора IRR на кредитоспособность инвестиционного проекта, однако оценить должным образом качество полученных моделей и гипотез на текущий момент не представляется возможным в связи с ограниченностью данных.

Приведенные алгоритмы и модели могут быть использованы банками при разработке собственных рейтинговых моделей оценки кредитоспособности сделок проектного финансирования на основе внутренних рейтингов (IRB Approach). При этом каждой кредитной организации необходимо учитывать специфику своего кредитного портфеля инвестиционных проектов. Целесообразность использования банками полученных в настоящей статье и статье (Карминский, Моргунов и Богданов, 2015) результатов может быть проверена самими банками исключительно по итогам проведения валидации моделей на своих инвестиционных проектах. 
Приложение

Описательная статистика

\begin{tabular}{|c|c|c|c|c|}
\hline Риск-фактор & Минимум & Максимум & Среднее значение & Стандартное отклонение \\
\hline LTV & 0,00 & 27,14 & 1,58 & 3,57 \\
\hline $\begin{array}{c}\text { Доля собств. участия } \\
\text { бенефициаров }\end{array}$ & $0,00 \%$ & $66,00 \%$ & $26,22 \%$ & $15,67 \%$ \\
\hline IRR & $10,00 \%$ & $94,00 \%$ & $23,79 \%$ & $14,97 \%$ \\
\hline DSCR & 1,00 & 221,21 & 4,89 & 23,95 \\
\hline LLCR & 0,00 & 1546,04 & 25,73 & 174,97 \\
\hline $\begin{array}{c}\text { Срок жизни проекта } \\
\text { (лет) }\end{array}$ & 0,75 & 7,01 & 3,45 & 1,88 \\
\hline
\end{tabular}

Корреляционная матрица (обучающая выборка)

\begin{tabular}{|c|c|c|c|c|c|}
\hline Переменная & $\begin{array}{c}\text { Доля собств. участия } \\
\text { бенефициаров }_{\text {Norm }}\end{array}$ & $\mathrm{IRR}_{\mathrm{Norm}}$ & $\mathrm{DSCR}_{\text {Norm }}$ & $\begin{array}{c}\text { Индустриальный } \\
\text { фактор }_{\text {Norm }}\end{array}$ & $\begin{array}{c}\text { Региональный } \\
\text { фактор }_{\text {Norm }}\end{array}$ \\
\hline $\begin{array}{l}\text { Доля собств. участия } \\
\text { бенефициаров }_{\text {Norm }}\end{array}$ & 1 & $-0,1108$ & $-0,1582$ & $-0,0736$ & 0,0005 \\
\hline $\mathrm{IRR}_{\text {Norm }}$ & $-0,1108$ & 1 & 0,0677 & 0,0529 & 0,036 \\
\hline $\mathrm{DSCR}_{\text {Norm }}$ & $-0,1582$ & 0,0677 & 1 & 0,111 & 0,0222 \\
\hline $\begin{array}{c}\text { Индустриальный } \\
\text { фактор }_{\text {Norm }}\end{array}$ & $-0,0736$ & 0,0529 & 0,111 & 1 & 0,1554 \\
\hline $\begin{array}{c}\text { Региональный } \\
\text { фактор }_{\text {Norm }}\end{array}$ & 0,0005 & 0,036 & 0,0222 & 0,1554 & 1 \\
\hline
\end{tabular}

Корреляционная матрица (оптимальная модель множественного выбора)

\begin{tabular}{|c|c|c|c|c|}
\hline Переменная & $\begin{array}{c}\text { Доля собств. участия } \\
\text { бенефициаров }{ }_{\text {Norm }}\end{array}$ & IRR $_{\text {Norm }}$ & $\begin{array}{c}\text { Индустриальный } \\
\text { фактор }_{\text {Norm }}\end{array}$ & $\begin{array}{c}\text { Региональный } \\
\text { фактор }_{\text {Norm }}\end{array}$ \\
\hline $\begin{array}{c}\text { Доля собств. участия } \\
\text { бенефициаров }_{\text {Norm }}^{*}\end{array}$ & 1 & $-0,0990$ & $-0,0769$ & $-0,0013$ \\
\hline IRR $_{\text {Norm }}$ & $-0,0990$ & 1 & 0,0489 & 0,0388 \\
\hline $\begin{array}{c}\text { Индустриальный } \\
\text { фактор }\end{array}$ & $-0,0769$ & 0,0489 & 1 & 0,1554 \\
\hline $\begin{array}{c}\text { Региональный } \\
\text { фактор }\end{array}$ & $-0,0013$ & 0,0388 & 0,1554 & 1 \\
\hline
\end{tabular}

Модель 1

\begin{tabular}{|c|c|c|c|c|c|c|c|c|c|}
\hline 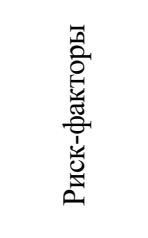 & 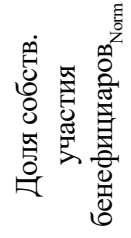 & 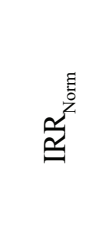 & 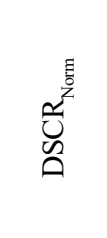 & 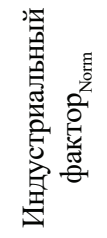 & 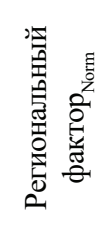 & & 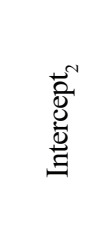 & 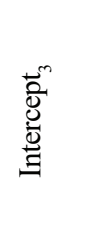 & 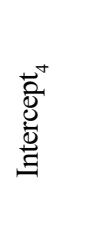 \\
\hline $\begin{array}{c}\text { Значение } \\
\text { регр. } \\
\text { коэфф. }\end{array}$ & 1,3184 & $-1,5333$ & $-0,1611$ & $-1,5956$ & $-1,2146$ & $-4,7838$ & $-1,1980$ & 2,0450 & 3,8996 \\
\hline P-value & $0,00 \%$ & $0,00 \%$ & $47,98 \%$ & $0,00 \%$ & $0,00 \%$ & $0,00 \%$ & $0,09 \%$ & $0,00 \%$ & $0,00 \%$ \\
\hline Std. error & 0,2772 & 0,2984 & 0,2280 & 0,3140 & 0,2650 & 0,7033 & 0,3605 & 0,4056 & 0,5831 \\
\hline $\begin{array}{l}\text { Кол-во на- } \\
\text { блюдений }\end{array}$ & 85 & & & & & & & & \\
\hline $\begin{array}{c}\text { AR } \\
\text { (Sommer's } \\
\text { D) }\end{array}$ & $79,82 \%$ & & & & & & & & \\
\hline $\log L$ & $-75,3340$ & & & & & & & & \\
\hline Pseudo-R ${ }^{2}$ & 0,4053 & & & & & & & & \\
\hline
\end{tabular}


Модель 2

\begin{tabular}{|c|c|c|c|c|c|c|c|c|}
\hline 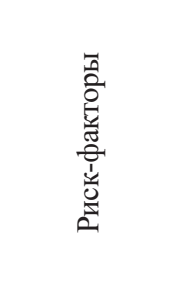 & 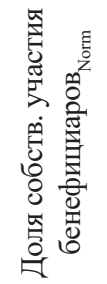 & 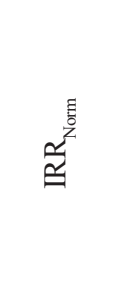 & 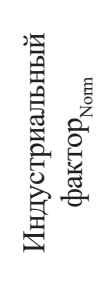 & 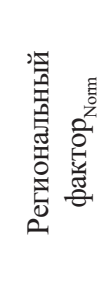 & 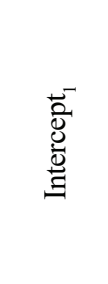 & 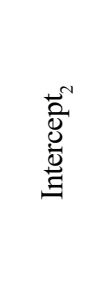 & 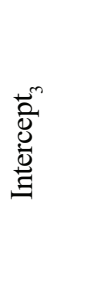 & 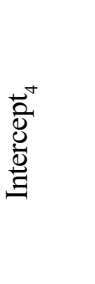 \\
\hline $\begin{array}{c}\text { Значение } \\
\text { регр. коэфф. }\end{array}$ & 1,3412 & $-1,5451$ & $-1,5995$ & $-1,2176$ & $-4,7551$ & $-1,2111$ & 2,0438 & 3,8850 \\
\hline P-value & $0,00 \%$ & $0,00 \%$ & $0,00 \%$ & $0,00 \%$ & $0,00 \%$ & $0,08 \%$ & $0,00 \%$ & $0,00 \%$ \\
\hline Std. error & 0,2760 & 0,2987 & 0,3132 & 0,2659 & 0,6940 & 0,3616 & 0,4064 & 0,5788 \\
\hline Кол-во на- & 85 & & & & & & & \\
\hline
\end{tabular}

\begin{tabular}{|c|c|c|c|c|c|c|c|c|}
\hline 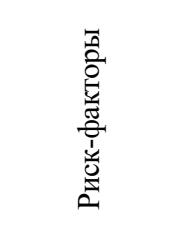 & 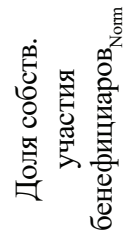 & 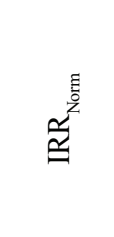 & 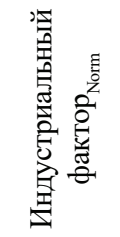 & 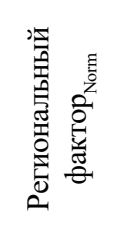 & $\begin{array}{l}\overleftarrow{0} \\
\stackrel{0}{0} \\
\stackrel{\Xi}{\Xi}\end{array}$ & $\begin{array}{l}\tilde{0}_{0}^{N} \\
\stackrel{0}{0} \\
\stackrel{\Xi}{\Xi}\end{array}$ & 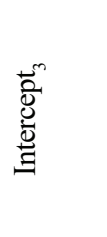 & 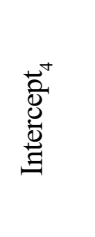 \\
\hline $\begin{array}{c}\text { Значение } \\
\text { регр. коэфф. }\end{array}$ & 1,3742 & $-1,6121$ & $-1,6268$ & $-1,2319$ & $-4,8329$ & $-1,2418$ & 2,0858 & 3,9699 \\
\hline P-value & $0,00 \%$ & $0,00 \%$ & $0,00 \%$ & $0,00 \%$ & $0,00 \%$ & $0,07 \%$ & $0,00 \%$ & $0,00 \%$ \\
\hline Std. error & 0,2792 & 0,3033 & 0,3160 & 0,2681 & 0,7034 & 0,3674 & 0,4137 & 0,5913 \\
\hline
\end{tabular}

Модель 2.2

\begin{tabular}{|c|c|c|c|c|c|c|c|c|}
\hline 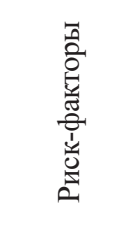 & 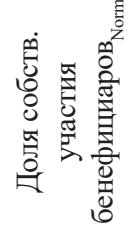 & 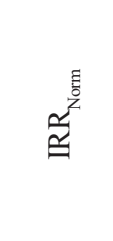 & 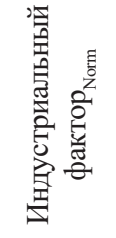 & 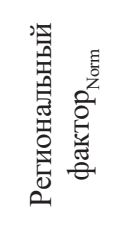 & 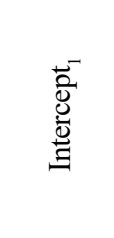 & 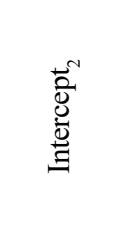 & 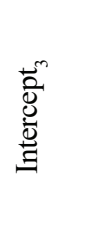 & 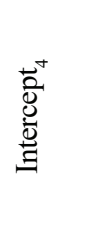 \\
\hline $\begin{array}{c}\text { Значение } \\
\text { регр. } \\
\text { коэфф. }\end{array}$ & 1,3709 & $-1,6000$ & $-1,6299$ & $-1,2333$ & $-4,8237$ & $-1,2447$ & 2,0874 & 3,9699 \\
\hline $\mathrm{P}$-value & $0,00 \%$ & $0,00 \%$ & $0,00 \%$ & $0,00 \%$ & $0,00 \%$ & $0,07 \%$ & $0,00 \%$ & $0,00 \%$ \\
\hline Std. error & 0,2792 & 0,3021 & 0,3161 & 0,2681 & 0,7011 & 0,3680 & 0,4133 & 0,5907 \\
\hline
\end{tabular}

눙

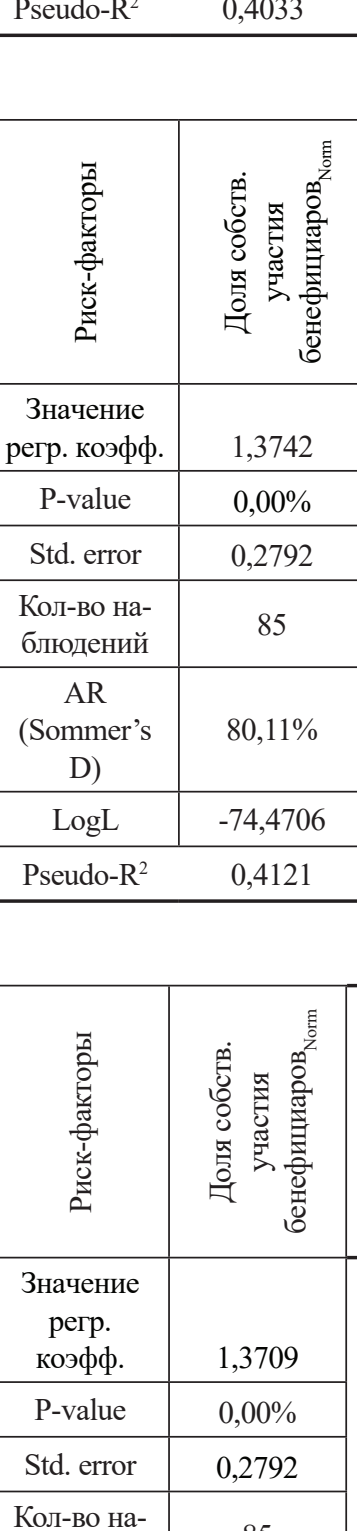

\begin{tabular}{|c|c|}
\hline $\begin{array}{c}\text { Кол-во на- } \\
\text { блюдений }\end{array}$ & 85 \\
\hline $\begin{array}{c}\mathrm{AR} \\
\text { (Sommer's } \\
\mathrm{D})\end{array}$ & $79,82 \%$ \\
\hline LogL & $-75,5797$ \\
\hline Pseudo-R ${ }^{2}$ & 0,4033 \\
\hline
\end{tabular}

\section{Модель 2.1}




\begin{tabular}{|c|c|c|c|c|c|c|c|c|}
\hline 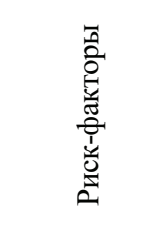 & 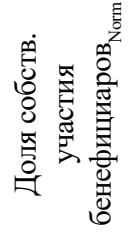 & $\frac{\sqrt[\Xi]{2}}{\underline{\underline{z}}}$ & 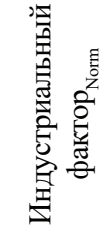 & 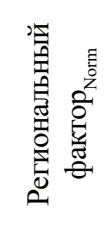 & 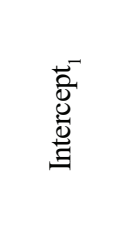 & $\begin{array}{l}\tilde{J}^{N} \\
\stackrel{0}{0} \\
\stackrel{\Xi}{\Xi}\end{array}$ & $\begin{array}{l}\overleftarrow{0}_{0}^{m} \\
\stackrel{0}{0} \\
\stackrel{\Xi}{\Xi}\end{array}$ & 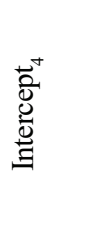 \\
\hline $\begin{array}{c}\text { Значение } \\
\text { регр. коэфф. }\end{array}$ & 1,3436 & $-1,5564$ & $-1,5961$ & $-1,2157$ & $-4,7631$ & $-1,2076$ & 2,0418 & 3,8841 \\
\hline P-value & $0,00 \%$ & $0,00 \%$ & $0,00 \%$ & $0,00 \%$ & $0,00 \%$ & $0,08 \%$ & $0,00 \%$ & $0,00 \%$ \\
\hline Std. error & 0,2760 & 0,2999 & 0,3130 & 0,2659 & 0,6960 & 0,3610 & 0,4067 & 0,5793 \\
\hline
\end{tabular}

\begin{tabular}{|c|c|}
\hline $\begin{array}{c}\text { Кол-во на- } \\
\text { блюдений }\end{array}$ & 85 \\
\hline $\begin{array}{c}\mathrm{AR} \\
\text { (Sommer's } \\
\mathrm{D})\end{array}$ & $79,59 \%$ \\
\hline LogL & $-75,5131$ \\
\hline Pseudo-R ${ }^{2}$ & 0,4039 \\
\hline
\end{tabular}

Корреляционная матрица (валидационная выборка - модель бинарного выбора)

\begin{tabular}{|c|c|c|c|c|}
\hline Переменная & $\begin{array}{c}\text { Доля собств. участия } \\
\text { бенефициаров }\end{array}$ & $\mathrm{IRR}_{\text {Norm }}$ & $\begin{array}{c}\text { Индустриальный } \\
\text { фактор }_{\text {Norm }}\end{array}$ & $\begin{array}{c}\text { Региональный } \\
\text { фактор }_{\text {Norm }}\end{array}$ \\
\hline $\begin{array}{c}\text { Доля собств. участия } \\
\text { бенефициаров }\end{array}$ & 1 & $-0,1555$ & $-0,0390$ & $-0,0414$ \\
\hline NRR $_{\text {Norm }}$ & $-0,1555$ & 1 & 0,0547 & 0,2494 \\
\hline $\begin{array}{c}\text { Индустриальный } \\
\text { фактор }\end{array}$ & $-0,0390$ & 0,0547 & 1 & 0,1343 \\
\hline $\begin{array}{c}\text { Регт } \\
\text { фактольр }\end{array}$ & $-0,0414$ & 0,2494 & 0,1343 & 1 \\
\hline
\end{tabular}

Корреляционная матрица (валидационная выборка - модель множественного выбора)

\begin{tabular}{|c|c|c|c|c|}
\hline Переменная & $\begin{array}{c}\text { Доля собств. участия } \\
\text { бенефициаров }\end{array}$ & IRR $_{\text {Norm }}^{*}$ & $\begin{array}{c}\text { Индустриальный } \\
\text { фактор }_{\text {Norm }}\end{array}$ & $\begin{array}{c}\text { Региональный } \\
\text { фактор }_{\text {Norm }}\end{array}$ \\
\hline $\begin{array}{c}\text { Доля собств. участия } \\
\text { бенефициаров }_{\text {Norm }}\end{array}$ & 1 & $-0,1433$ & $-0,0393$ & $-0,0425$ \\
\hline IRR* $_{\text {Norm }}$ & $-0,1433$ & 1 & 0,0441 & 0,2530 \\
\hline Индустриальный фактор $_{\text {Norm }}$ & $-0,0393$ & 0,0441 & 1 & 0,1343 \\
\hline Региональный фактор $_{\text {Norm }}$ & $-0,0425$ & 0,2530 & 0,1343 & 1 \\
\hline
\end{tabular}

\section{Список литературы}

1. База данных Руслана - база данных Bureau van Dijk (https://ruslana.bvdep.com/ version-201623/home.serv?product=ruslana).

2. Банк России. Письмо от 29.12.2012 № 192-Т «О Методических рекомендациях по реализации подхода к расчету кредитного риска на основе внутренних рейтингов банков» // Справочно-правовая система «Консультант Плюс»: [Электронный ресурс].

3. Власов А., Помазанов М. Калибровка национальных рейтинговых систем. URL: http:// www.rusipoteka.ru/files/articles/pomazanov.pdf. 2008.

4. Жевага А.А., Моргунов А.В. Использование сводных макроэкономических индикаторов для калибровки внутренних рейтинговых моделей в банках // Деньги и кредит. 2015. № 8. C. 39-46.

5. Карминский А.М. Кредитные рейтинги и их моделирование. М.: Изд. дом НИУ ВШЭ, 2015.

6. Карминский А.М., Костров А.В. Моделирование вероятности дефолта российских банков: расширенные возможности // Журнал новой экономической ассоциации. 2013. № 1, т. 17. С. 64-86. 
7. Карминский А.М., Моргунов А.В., Богданов П.М. Оценка вероятности дефолта сделок проектного финансирования //Журнал Новой экономической ассоциации. 2015. №2, т. 26. C. 99-122.

8. Карминский А.М., Фалько С.Г. Контроллинг в банке / под ред. А.М. Карминского, С.Г. Фалько. М.: ИД «ФОРУМ»: ИНФРА-М, 2013.

9. Кокс Д., Льюис П. Статистический анализ последовательностей событий. М.: Мир, 1969.

10. Кокс Д., Оукс Д. Анализ данных типа времени жизни. М.: Финансы и статистика, 1988.

11. Лобанов А.А., Чугунов А.В. Энциклопедия финансового риск-менеджмента. М.: АльпинаБизнесБукс, 2009.

12. Моргунов А.В., Жевага А.А. Контроллинг кредитных рисков в коммерческом банке // Контроллинг. 2015. №2, т. 56. С. 70-78.

13. Полтерович В.М. Стратегия модернизации российской экономики. СПб: Алетейя, 2010.

14. Тотьмянина К.М. Моделирование вероятности дефолта корпоративных заемщиков банков. Дисс. ... кандидата наук. М.: НИУ ВШЭ, 2014.

15. Allen, S. (2003), "Financial risk management: A practioner's guide to managing market and credit risk". Hoboken, N.J.: John Wiley \& Sons, Inc.

16. Basel Committee on Banking Supervision. Basel III: A global regulatory framework for more resilient banks and banking system. (2011). Bank for International Settlements, Mode of Access: http://www.bis.org/publ/bcbs189.pdf.

17. Gatti, S. (2013), "Project Finance in Theory and Practice" Second Edition. DOI: http://www. sciencedirect.com/science/book/9780123919465

18. Jorion, P. (2007), "Financial risk manager instruction manual". 4th ed. N.Y.: John Wiley \& Sons, Ltd.

19. Kayser, D. (2013), "Recent research in project finance a commented bibliography", Procedia Computer Science, no. 17, pp. 729-736. 20. Laishram, B., and Kalidindi, S. (2009), "Desirability rating analysis for debt financing of public-privatepartnership road projects", Construction Management \& Economics, vol.9, no. 27, pp. 823-837.

20. Peresetsky, A., Karminsky, A., and Golovan, S. (2011), "Probability of default models of Russian banks", Economic Change and Restructuring, vol. 4, no. 44, pp. 297-334.

21. Siddiqi, N. (2006), "Credit Risk Scorecards Developing and Implementing Intelligent Credit Scoring”, published by John Wiley \& Sons, Inc., Hoboken, New Jersey. 
Alexey Morgunov,

PhD student, National Research University Higher School of Economics

\begin{abstract}
This article discusses the basic approaches used in modeling the assessment of default probability for investment projects in the commercial bank with the framework of internal ratings based (IRB) approach. Model of estimation the probability of default for project finance transactions based on Russian statistics was developed using the econometric model of multiple choice. The validation of the developed model and the earlier model (developed with using the statistics of defaults) was done.

The main objectives of the research: analysis of different methods of estimating the probability of default of investment projects; the practical application of the method of multiple choice for Russian investment projects (previously the author used the method of binary choice, the results of the practical application of which is published in 2015 in the journal of the New Economic Association» №2(26)) and comparison between methods of binary and multiple choice in accordance with the results of the validation using wellknown validation characteristics and criterias. In this article the basic approaches used in modeling the assessment of default probability for investment projects in a commercial bankes in the framework of the approach based on internal ratings (IRB Approach) were discussed. The results of the research connected with building models to estimate the probability of default for project finance transactions using multiple-choice method with high accuracy ratios (discriminatory ability) and stability (t-student test performed with confidence probability more then $85 \%$ ) and obtaining a quantitative comparison of the quality of the developed model of multiple choice with the quality of the previously developed model of binary choice. Obtained algorithms and models may be used by credit institutions to develope rating models based on internal ratings (IRB Approach). The feasibility of using the obtained results may be checked by banks according to results of the validation of the models on their own credit portfolios of investment projects. By results of research the conclusions about reasonability of application of the methods of binary and multiple choice to assess the creditworthiness of investment projects (the accuracy of the obtained models is high) and about the strong influence of IRR on the creditworthiness of the projects were made. However, the assessment of the quality of models and hypotheses is now impossible because of limited data.
\end{abstract}

Keywords: default, binary logistic regression, multinomial logistic regression, discriminatory power, calibration, validation

JEL: G21, G24, G32.

\title{
References
}

1. Allen, S. (2003), “Financial risk management: A practioner's guide to managing market and credit risk”. Hoboken, N.J.: John Wiley \& Sons, Inc.

2. Bank Rossii (2012), Pis’mo ot 29.12.2012 № 192-T “O Metodicheskikh rekomendatsiyakh po realizatsii podkhoda $\mathrm{k}$ raschetu kreditnogo riska na osnove vnutrennikh reytingov bankov". Spravochno-pravovaya sistema "Konsul'tant Plyus". Kompaniya "Konsul'tant Plyus".

3. Basel Committee on Banking Supervision. Basel III: A global regulatory framework for more resilient banks and banking system. (2011). Bank for International Settlements, Mode of Access: http://www.bis.org/publ/bcbs189.pdf.

4. Gatti, S. (2013), "Project Finance in Theory and Practice" Second Edition. DOI: http:// www.sciencedirect.com/science/book/9780123919465 
5. Hait, M. (2008), "Project finance and structured finance: cash flow models with Financial Covenants". Accessed: www.finance-dms.com/stable/fin_covenants.html.

6. Jorion, P. (2007), “Financial risk manager instruction manual”. 4th ed. N.Y.: John Wiley \& Sons, Ltd.

7. Karminskiy A.M. (2015), "Credit ratings and their modeling”, M.: Izdatel'skiy dom "National Research University Higher School of Economics"

8. Karminskiy A.M., Fal'ko S.G. (2013), “Controlling in the Bank”, M.: Izdatel'skiy dom "FORUM", "INFRA-M».

9. Karminskiy A.M., Kostrov A.V. (2013), "Modeling the Default Probabilities of Russian Banks: Extended Abilities", Journal of the New Economic Association, vol. 17, no. 1, pp. 64-86.

10. Karminskiy A.M., Morgunov A.V., Bogdanov P.M. (2015), "The Assessment of Default Probability for the Project Finance Transactions", /The Journal of New Economic Association, vol.2, no. 26, pp. 99-122.

11. Kayser, D. (2013), "Recent research in project finance a commented bibliography", Procedia Computer Science, no. 17, pp. 729-736.

12. Koks D., Lewis P. (1969), "Statistical analysis of sequences of events”, M.: Mir.

13. Koks D., and Oaks D. (1988), "Data analysis of life time type”, M.: Finance and statistic.

14. Laishram, B., and Kalidindi, S. (2009), "Desirability rating analysis for debt financing of public-privatepartnership road projects", Construction Management \& Economics, vol.9, no. 27, pp. 823-837.

15. Lobanov, A.A., Chugunov, A.V. (2009), "Encyclopedia of financial risk management", M.: Al'pina Biznes Buks.

16. Morgunov, A.V., Zhevaga, A.A. (2015), "Controlling credit risk in a commercial bank", Controlling, vol.2, no. 56, pp. 70-78.

17. Peresetsky, A., Karminsky, A., and Golovan, S. (2011), "Probability of default models of Russian banks", Economic Change and Restructuring, vol. 4, no. 44, pp. 297-334.

18. Ruslana Database of Bureau van Dijk (https://ruslana.bvdep.com/version-201623/home. serv?product=ruslana).

19. Siddiqi, N. (2006), "Credit Risk Scorecards Developing and Implementing Intelligent Credit Scoring”, published by John Wiley \& Sons, Inc., Hoboken, New Jersey.

20. Tot'myanina K.M. (2014), "Modeling Probability of Default for Corporate Borrowers of Banks”, PhD Dissertation ... National Research University Higher School of Economics.

21. "The strategy of modernization of the Russian economy" (2010), Polterovich V.M. (ed.). SPb: Aleteya.

22. Vlasov A., Pomazanov M. (2008), "Calibration of national rating system". Available at: http://www.rusipoteka.ru/files/articles/pomazanov.pdf.

23. Zhevaga A.A., Morgunov A.V. (2015), "The use of aggregated macroeconomic indicators during calibration of internal rating models at banks", Den'gi i kredit, no.8. pp. 39-46. 